\title{
Off-field Transportation and Storage of Corn Stover with Medium-high Moisture Content Based on the Multistage Continuous Cold Roll Forming Method
}

\author{
Ning Ding, ${ }^{\mathrm{a}}$ Haitao Li, ${ }^{\mathrm{a}, \mathrm{b}, *}$ An Yan, ${ }^{\mathrm{a}}$ Shouzhong Li, ${ }^{\mathrm{a}}$ Pingyi Liu, ${ }^{\mathrm{a}}$ and Wenjun Wei ${ }^{\mathrm{a}}$ \\ The moisture content of corn stover during the harvest season in the \\ Huang-Huai-Hai region of China is approximately $50 \%$. To achieve rapid \\ off-field transportation and to prolong its shelf life, a method suitable for \\ corn stover with medium-high moisture content was considered based on \\ the stover multistage continuous cold roll forming method. An orthogonal \\ experiment was adopted by taking the moisture content, sterilization \\ method, and inhibitor addition method as experimental factors and taking \\ the shelf life, percent rebound, and density of the molding blocks as the \\ experimental indices. It was found that the steam sterilization method can \\ prolong the shelf life of the molding block the most. The percent rebound \\ and the density were primarily affected by the moisture content, followed \\ by the sterilization method. A comprehensive analysis indicated that the \\ optimal treatment mode was a moisture content of $45 \%$, and the optimal \\ sterilization method was steam sterilization with no inhibitor. In this mode, \\ the molding block can be stored for $72 \mathrm{~h}$ without mildew with an average \\ temperature of $32{ }^{\circ} \mathrm{C}$ and an average humidity of $48 \%$ during the day. The \\ percent rebound was $24.3 \%$, and the density can reach $310 \mathrm{~kg} / \mathrm{m}^{3}$ after \\ the completion of rebound.
}

Keywords: Corn stover; Roll forming; Rapid off-field; Shelf life; Orthogonal experiment

Contact information: a: College of Engineering, China Agricultural University, Beijing 100083, China; b: Beijing Key Laboratory of Modern Agricultural Equipment Optimization, China Agricultural University, Beijing 100083, China; *Corresponding author: h.li@cau.edu.cn

\section{INTRODUCTION}

China's corn stover resources represent a large output, accounting for $46.6 \%$ of China's agricultural residues (Tan et al. 2019). In China, the off-field utilization of corn stover primarily consists of feed and fuels. According to the moisture content of the harvest season, corn stover can be divided into four categories: high moisture content $(>60 \%)(\mathrm{Wu}$ et al. 2016), medium-high moisture content ( $40 \%$ to $60 \%$ ), medium-low moisture content ( $20 \%$ to $40 \%$ ), and low moisture content $(<20 \%)$. Among these categories, corn stover with high moisture content is primarily used for silage, while stover with medium-low moisture content and low moisture content is primarily made into briquettes or fuels through solidification technology (Bi et al. 2019). China's corn-growing areas are primarily distributed in the Northeast and Huang-Huai-Hai regions (Zuo et al. 2015). The HuangHuai-Hai region primarily adopts the planting mode of summer corn and winter wheat twice a year, and the moisture content of corn stover in the harvest season is approximately $50 \%$ (Zhai 2013). Because the output of corn stover is too large, on-site drying not only consumes considerable manpower and space but additionally affects subsequent planting. Therefore, corn stover needs to be removed from the field quickly. Corn stover with this moisture content has low bulk density, has high transportation costs, and decays easily, 
making it difficult to guarantee the storage quality and safety of corn stover when it is transported to the pastoral region of Northwest China (Xiong et al. 2010; Wu et al. 2016). This difficulty in transportation has led to the problem of high corn stover yields that are difficult to handle in China's planting areas, while the feed gap in the northwestern pastoral areas is large and difficult to address (Dong et al. 2018).

The key to efficient utilization of stover resources is to rely on biomass compacting technology to reduce volume and increase density. Of the compaction methods, mechanical compaction is the most effective (Tumuluru et al. 2011; Guo et al. 2016). According to the molding density of the material, the existing compression can be divided into three types: high density, medium-low density, and low density. Among these types, the compression molding of the die roller type biomass material is used for high-density molding, and the molding density is usually above $600 \mathrm{~kg} / \mathrm{m}^{3}$ (Ouyang et al. 2011), but this mode is only suitable for the molding of straw with low moisture content (Xia et al. 2014; Ning et al. 2016). The square baler is a medium-low density molding technique. The molding density achieved by the square baler is usually greater than $180 \mathrm{~kg} / \mathrm{m}^{3}$ according to the moisture content of the straw (Wang et al. 2009). The piston reciprocating punching affects the efficiency of this baler, and the equipment investment cost is high (Qian et al. 2019). The round baler is used for low-density molding. The molding density is usually above 125 $\mathrm{kg} / \mathrm{m}^{3}$ depending on the moisture content of the straw (Liu et al. 2017). However, the intermittent operation mode of the round baler causes round bales to exhibit low productivity and poor density uniformity (Guo et al. 2018; Xie et al. 2019). In the straw multistage continuous cold roll forming method described in this article, according to the different moisture contents of straw, the forming density is mainly within the range 250 to $400 \mathrm{~kg} / \mathrm{m}^{3}$, which is classified as medium density forming (Liu et al. 2016).

Scholars from various countries have performed considerable research in the field of stover biomass formation and storage. Kaliyan et al. (2013) studied the effects of different materials (corn stover and perennial grasses), particle size, and roller force on the density and durability of the molding blocks. The results showed that the roller force had the strongest effect on the density and durability of the molding blocks. The density of briquettes produced by the roller press was greater than $240 \mathrm{~kg} / \mathrm{m}^{3}$, and the briquettes exhibited good durability. Gao et al. (2015) designed a round bale forming device for corn stover silage with high moisture content based on the logarithmic spiral round bale forming principle. It tested the effect of the pressure angle of the feeding precompression mechanism and stover moisture content on the baling performance of the device. The results showed that the use of a logarithmic spiral round bale forming device with a certain pressure angle can solve the congestion problem and reduce the baling time. Cong et al. (2009a, 2009b) developed the 4YQK-2 corn harvester of stalk silage bundled based on the existing corn harvesting and forage silage mechanization technology and tested the performance of the prototype. The results of the study showed that the prototype can effectively complete the work of collecting, shredding, conveying, and bundling stover with high moisture content.

Corn stover with medium-high moisture content easily deteriorates under natural conditions without treatment. There are usually two ways to store this biomass. One approach is to make silage or yellow feed, which can be stored for a long time, and the other method is to reduce the moisture content of the stover by air drying followed by stacking or compression storage. Przybył et al. (2018) explored the effects of different treatment technologies on the quality of corn stover silage, and their results showed that silage can effectively improve the quality and storage time of corn stover feed. The corn 
stover silage in a flexible silo exhibited the best quality. Shinners et al. (2003) studied the effects of different storage methods on the storage quality of dry and wet corn stover, and their results showed that both bagging and film-coated silage of high-moisture stover were beneficial to storage, and film-coated silage was less prone to mold. Tian et al. (2015) explored the effects of three different storage methods (open-air, covered, and sealed) on the long-term storage of low-moisture corn stover with such pretreatment methods as whole plant, baling, and crushing. The results showed that the whole plant or baled stover were preferable, and the environment should be well ventilated when storing large quantities of stover. However, all the above methods require considerable time and labor, which are not conducive to the efficient and rapid transportation and reuse of corn stover from the fields in the Huang-Huai-Hai region of China.

Therefore, this research had the following objectives: (a) Verify the feasibility of the multistage continuous cold roll forming method for corn stover with medium-high moisture content; (b) Employ the experimental prototype to prolong the shelf life of corn stover with medium-high moisture content; (c) Explore the influence of moisture content, sterilization method and inhibitor addition method on the storage capacity of stover molding blocks; and (d) Obtain a treatment method suitable for the rapid off-field transportation of corn stover with medium-high moisture content to solve the problem of processing corn stover with medium-high moisture content in the Huang-Huai-Hai region of China.

\section{EXPERIMENTAL}

\section{Materials}

Corn stover was obtained from Gaocheng District, Shijiazhuang city, Hebei Province, China, in late June 2020, and it was crushed by the 9FS5-5500 straw kneading and crushing machine produced by China Shijiazhuang Liang New Energy Technology Co., Ltd. (Shijiazhuang, China) (Fig. 1).

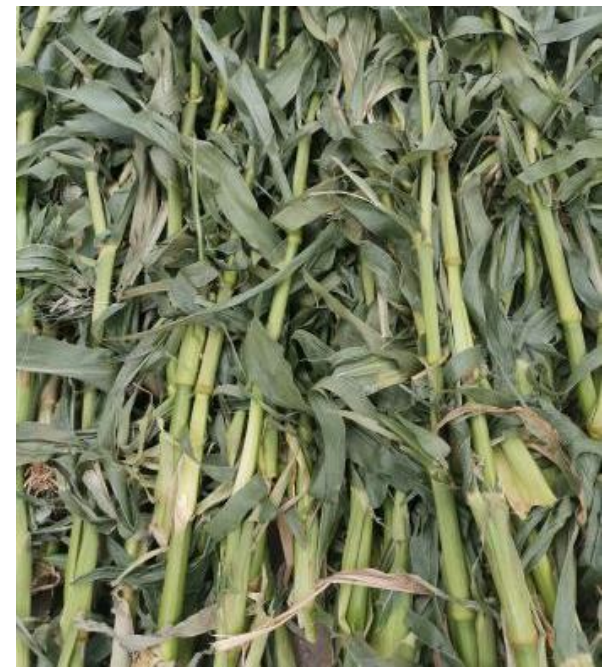

(a)

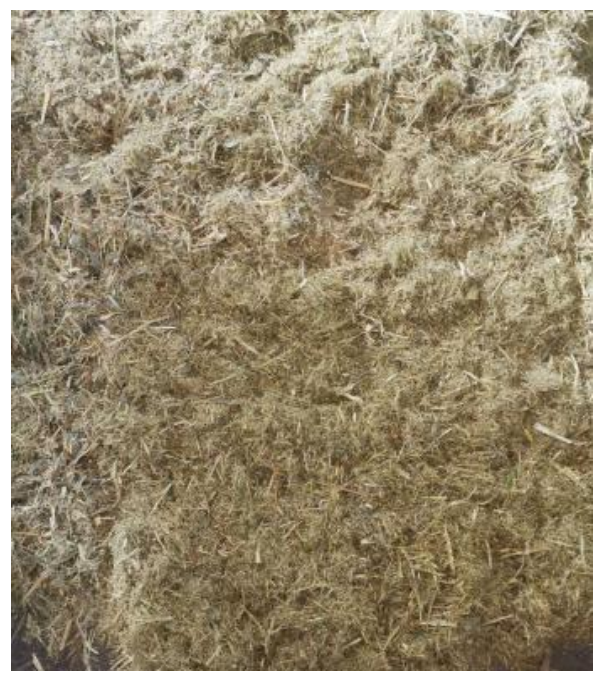

(b)

Fig. 1. Corn stover for experiment: (a) untreated corn stover; (b) corn stover after being crushed 
The study was conducted by China Hebei Nongle New Energy Technology Co., Ltd. (Shijiazhuang, China) in July 2020. The average temperature of the experimental environment was $32{ }^{\circ} \mathrm{C}$, and the average humidity was $48 \%$.

\section{Devices}

Structure and working principle of a stover multistage continuous cold roll forming machine

The assembly drawing and prototype of the molding machine are presented in Fig. 2. The prototype of this molding machine was independently developed by China Agricultural University.
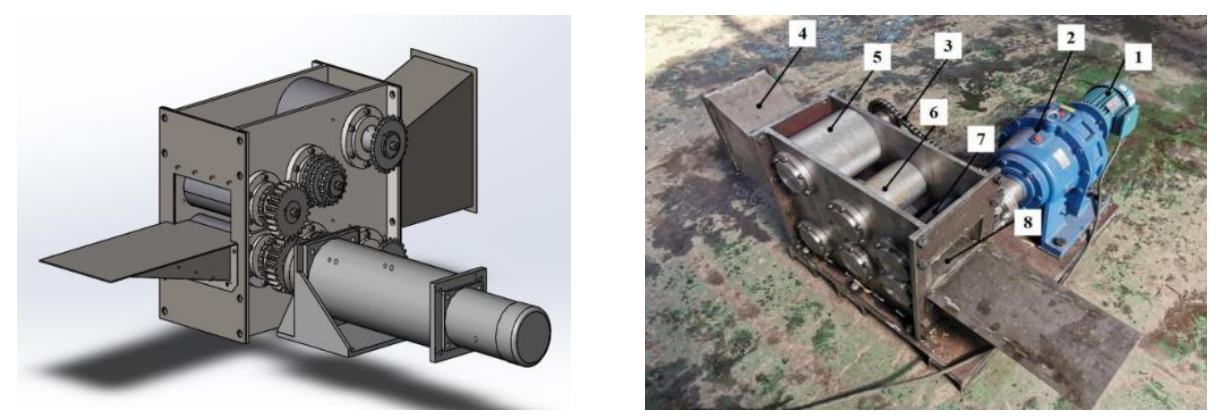

Fig. 2. Assembly drawing and prototype of a stover multistage continuous cold roll forming machine: 1: motor; 2: reducer; 3: transmission system; 4: feeding port; 5: one-stage compression roller; 6: two-stage compression roller; 7: three-stage compression roller; and 8: outlet

The working principle is shown in Fig. 3.

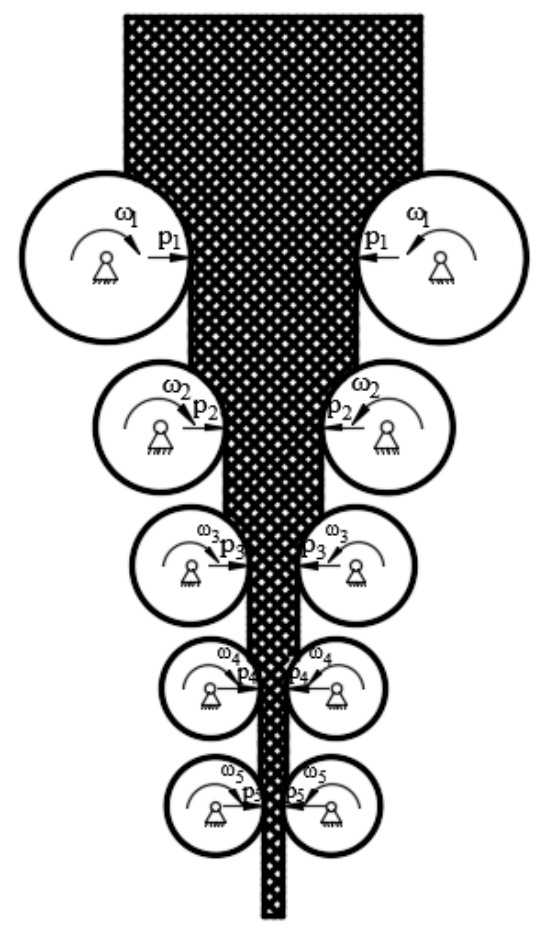

Fig. 3. Schematic diagram of the design scheme of a stover multistage continuous cold roll forming machine 
The crushed corn stalks are fed in from one end and are continuously compressed by multistage symmetrically arranged compression rollers and are then discharged from the other end. The pressure at each compression stage during the compression process of the stover material is represented by $p_{1-5}$. The rotation directions of the compression rollers at each stage are $\omega_{1}, \omega_{2}, \omega_{3}, \omega_{4}$, and $\omega_{5}$. Continuous roll forming of the crushed corn stover is employed to improve the productivity of compression forming and realize the efficient continuous cold compression forming of corn stover. The compression roller interacts with the stover material in the working process by rolling friction, and the stover material is cold-compressed, which can reduce the energy consumption of the machine. Finally, the symmetrical arrangement of the compression rollers can offset the axial force, improve the stability of equipment operation, reduce the wear of various working parts, and increase the life of the whole machine.

According to the relationship between the total rolling ratio $\varepsilon$, the number of compression stages $n$, and the compression roll radius $r$, the machine follows the open compression characteristics of corn stover and the design method of steel rolling machinery (Huang et al. 2007; Wang et al. 2016a,b; Liu et al. 2019). At the same time, to conserve experimental prototype consumables and to reduce the size of the experiment prototype, the prototype machine only produces the third-stage compression molding part, and the front-end feeding and precompression part are completed by the precompression device. Finally, the parameters of the molding machine are optimized, as shown in Table 1.

Table 1. Parameters of the Stover Multistage Continuous Cold Roll Forming Machine

\begin{tabular}{|c|c|}
\hline Name & Value \\
\hline Compression stages $(n /$ level $)$ & 3 \\
\hline $\begin{array}{c}\text { Thickness of the first-stage compression } \\
\text { roller enters the material }\left(s_{0} / \mathrm{mm}\right)\end{array}$ & 200 \\
\hline $\begin{array}{c}\text { Thickness of the final-stage compression } \\
\text { roller presses out the material }\left(s_{n} / \mathrm{mm}\right)\end{array}$ & 180 \\
\hline $\begin{array}{c}\text { Diameter of the first-stage compression } \\
\text { roller }\left(d_{1} / \mathrm{mm}\right)\end{array}$ & 125 \\
\hline $\begin{array}{c}\text { Diameter of the second-stage compression } \\
\text { roller }\left(d_{2} / \mathrm{mm}\right)\end{array}$ & 100 \\
\hline $\begin{array}{c}\text { Diameter of the third-stage compression roller } \\
\left(d_{3} / \mathrm{mm}\right)\end{array}$ & 63.61 \\
\hline $\begin{array}{c}\text { Feeding angle of the first-stage } \\
\text { compression roller }\left(\alpha_{1}{ }^{\circ}\right)\end{array}$ & 53.13 \\
\hline $\begin{array}{c}\text { Feeding angle of the second-stage } \\
\text { compression roller }\left(\alpha_{2}{ }^{\circ}\right)\end{array}$ & 45.57 \\
\hline $\begin{array}{c}\text { Feeding angle of the third-stage } \\
\text { compression roller }\left(\alpha_{3}{ }^{\circ}\right)\end{array}$ & 10 \\
\hline Total rolling ratio $(\varepsilon)$ & 2 \\
\hline First-stage compression ratio $\left(\varepsilon_{1}\right)$ & 2 \\
\hline Second-stage compression ratio $\left(\varepsilon_{2}\right)$ & 2.5 \\
\hline Third-stage compression ratio $\left(\varepsilon_{3}\right)$ & \\
\hline
\end{tabular}

\section{Other experimental equipment and instruments}

Other equipment and instruments required for the experiment included a homemade precompression device (China Agricultural University, Beijing, China), an OHAUS MB23 moisture analyzer (OHAUS Co., Parsippany, NJ, USA), a ZF-C10002 electronic balance 
(Hardware Weighing Apparatus Co., Hanghai, China), a LDR0.004-0.4 steam generator (Baishen Washing Equipment Co., Hanghai, China), a TUV ultraviolet germicidal lamp (Philips Investment Co., Amsterdam, Netherlands), a 3000-mL beaker, a temperature and humidity meter (Deli Group Co., Ningbo, China), a spray bottle, and a scale.

\section{Methods}

\section{Experimental preparation}

To explore the factors that affect the storage performance of corn stover blocks with medium-high moisture content, as well as to obtain a better processing mode that is convenient for transportation to different regions and adapts to this molding machine, an experimental study was conducted. Corn in the Huang-Huai-Hai area of China is generally harvested from the late wax maturity stage to the early maturity stage, and the moisture content of the harvested stover is approximately 50\%. According to a previous experiment, it was observed that when the corn stover material is watered too much or the corn stover moisture content is higher than $50 \%$, after being compressed by the stover multistage continuous cold roll forming machine, 'juice' appears (Fig. 4). It was found through calculation that the moisture content is largely stable at approximately $50 \%$ after the compression is completed. Therefore, this study chose three levels of moisture content: $40 \%, 45 \%$, and $50 \%$. To avoid the influence of the 'juice' on the experimental results and utilization of corn stover, this experimental study reduced the single stover feeding amount.
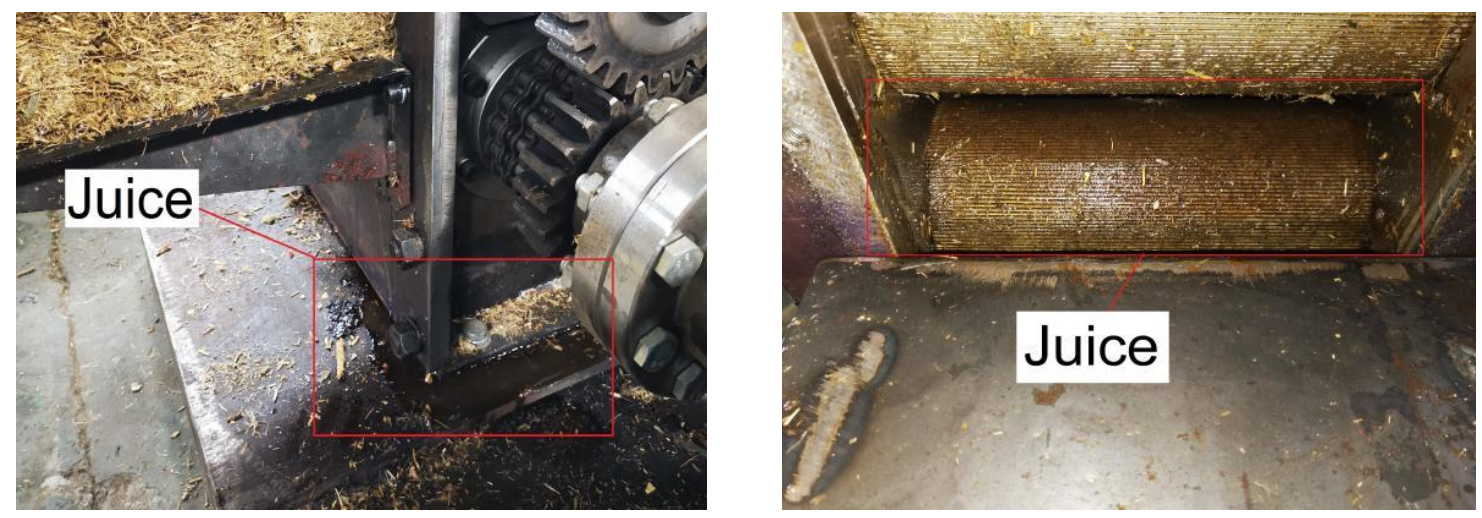

Fig. 4. 'Juice' appears in the compression process of corn stalks with moisture content higher than $50 \%$

Due to the large quantity of stover required for the experiment and to establish conditions closer to the natural situation, the moisture content of the corn stover used in the experiment was controlled by natural air drying. Three samples were randomly selected from each group, and the moisture content was measured with the MB23 moisture analyzer. The average value was calculated, and the maximum error between the measured moisture content and the target moisture content $(40 \%, 45 \%$, and $50 \%)$ was controlled to not exceed $1.0 \%$. The measurement of the MB23 moisture analyzer follows the principle of Eq. 1,

$$
M C=\frac{m_{0}-m_{1}}{m_{0}} \times 100 \%
$$

where $\mathrm{MC}$ is the moisture content $(\%), m_{0}$ is the initial mass of samples $(\mathrm{g})$, and $m_{1}$ is the mass of samples $(\mathrm{g})$ after drying. 


\section{Orthogonal experimental design}

To explore the effects of moisture content, sterilization methods, and inhibitor addition methods on the compression and storage performance of corn stover with medium-high moisture content, this study selected orthogonal table L9 $\left(3^{4}\right)$ for experiments. The various factors and levels are shown in Table 2.

Table 2. Experimental Factors and Levels

\begin{tabular}{|c|c|c|c|c|}
\hline \multirow{2}{*}{ Levels } & \multicolumn{4}{|c|}{ Factors } \\
\cline { 2 - 5 } & $\begin{array}{c}\text { Moisture } \\
\text { Content }(\mathrm{A})\end{array}$ & $\begin{array}{c}\text { Sterilization } \\
\text { Methods (B) }\end{array}$ & $\begin{array}{c}\text { Inhibitor } \\
\text { Addition } \\
\text { Methods (C) }\end{array}$ & $\begin{array}{c}\text { Empty } \\
\text { Column } \\
\text { (D) }\end{array}$ \\
\hline 1 & $40 \%$ & $\begin{array}{c}\text { No } \\
\text { processing }\end{array}$ & None added & $\mathrm{D}_{1}$ \\
\hline 2 & $45 \%$ & $\begin{array}{c}\text { Steam } \\
\text { sterilization }\end{array}$ & $\begin{array}{c}\text { Spray evenly } \\
\text { before } \\
\text { compression }\end{array}$ & $\mathrm{D}_{2}$ \\
\hline 3 & $50 \%$ & $\begin{array}{c}\text { UV } \\
\text { sterilization }\end{array}$ & $\begin{array}{c}\text { Surface spray } \\
\text { after molding }\end{array}$ & $\mathrm{D}_{3}$ \\
\hline
\end{tabular}

The goal of this research was to explore the optimal processing mode for rapid offfield transportation and storage of corn stover with medium-high moisture content. Therefore, under the premise of ensuring work efficiency, the materials should be sterilized as much as possible. Comprehensive considerations include steam sterilization, a steam temperature at the outlet above $120^{\circ} \mathrm{C}$, a sterilization time of 1 min (Iskakov et al. 2019), UV sterilization, a UV wavelength of $253.7 \mathrm{~nm}$, and a sterilization time of $15 \mathrm{~min}$ (Murata et al. 2008). The chemical composition of the inhibitor was potassium sorbate, which could effectively inhibit the activities of mold, yeast, and aerobic bacteria. Following the instruction manual, $2 \mathrm{~g}$ of inhibitor was added to $1 \mathrm{~kg}$ of material.

\section{Experimental indices}

(1) Shelf life: The shelf life of the stover molding block refers to the storage time of the naturally stacked stover compression molding block without mildew and odor. The shelf life of the molding block has a considerable influence on its transportation and storage capacity. Therefore, the molding block is naturally stacked in a dry and dark environment, the three-component blocks are randomly selected after the compression is completed, and the quality of the compressed blocks is manually checked every $4 \mathrm{~h}$. When there was clear mold visible to the naked eye, it was regarded as mold. The time interval between the moment when mold became apparent and the initial moment was defined as the shelf life of the molding block was measured, and the average value $t$ was obtained.

(2) Percent rebound: The percent rebound of the stover molding block refers to the change in the thickness of the molding block with time after the compression was completed. The rebound of the molding block is known to have a great impact on transportation. When the compression molding machine was in normal operation, the 3 molding blocks were randomly selected after the compression was completed at the exit of the molding machine, and the thickness of the molding block is checked every 5 min until the thickness no longer changed. The percent rebound was calculated according to Eq. 2, and the average value was obtained, 


$$
\lambda=\frac{s^{\prime \prime}-s^{\prime}}{s^{\prime \prime}} \times 100 \%
$$

where $\lambda$ is the percent rebound of the forming block (\%), $s$ " is the thickness of the forming block after rebound ( $\mathrm{mm})$, and $s$ ' is the thickness of the forming block after compression (mm).

(3) Density: When the compression molding machine operated normally, 3 groups of molding blocks were randomly selected after rebounding, their edges and corners were trimmed, parts with uniform density were left for weighing, and their length, width, and height were measured for volume calculation. The density was calculated according to Eq. 3 , and then the average value is determined,

$$
\rho=\frac{m}{V}
$$

where $\rho$ is the density of the forming block $\left(\mathrm{kg} / \mathrm{m}^{3}\right), m$ is the mass of the forming block $(\mathrm{kg})$, and $V$ is the volume of the forming block $(\mathrm{mm})$.

\section{Statistical analysis}

In each experiment, three sets of replicates were carried out under the same working condition, and the average value was obtained. Statistical tests were performed using the analysis of range and variance (ANOVA). The goal was to obtain the optimal combination. Statistical data analysis was conducted using SPSS 19.0 (IBM Corporation, Armonk, NY, USA).

\section{RESULTS AND DISCUSSION}

\section{Range Analysis of the Orthogonal Experiment Results}

Figure 5 shows the typical speciments of the molding block after the compression was completed, and the rebound was stable in the 9 groups of orthogonal experiments.

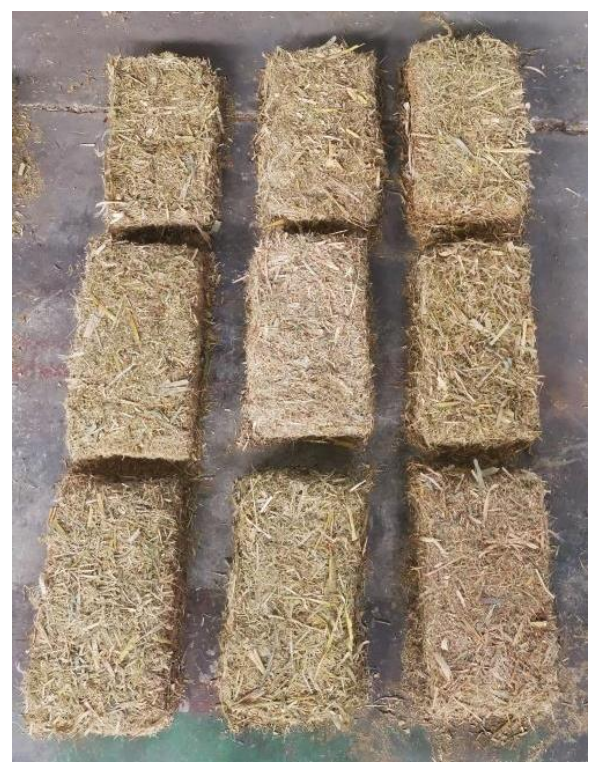

Fig. 5. Compression molding block samples 
The results of the orthogonal experiment are shown in Table 3. The three factors of corn stover moisture content, sterilization method, and inhibitor addition method were found to have different effects on the shelf life, percent rebound, and density of the compression molding block in the natural state. The range value reflects the effects of various factors on the index. From the range analysis, the sterilization method had a significant impact on the shelf life and density of the molding block. The moisture content of the material had a significant effect on the percent rebound and density of the molding block. The range analysis method was used to analyze the influence of the three factors on the three indices of the compression molding block's shelf life, percent rebound, and density. The effect of the error column on the test indexes was not considered temporarily.

Table 3. Orthogonal Experiment Results and Range Analysis

\begin{tabular}{|c|c|c|c|c|c|c|c|c|}
\hline \multirow{2}{*}{\multicolumn{2}{|c|}{ Serial Number }} & \multicolumn{4}{|c|}{ Factors } & \multicolumn{3}{|c|}{ Experimental Indices } \\
\hline & & A & B & C & D & Shelf Life & Percent & Density \\
\hline \multicolumn{2}{|l|}{1} & 2 & 1 & 2 & 3 & 44 & 30.93 & 255.46 \\
\hline \multicolumn{2}{|l|}{2} & 2 & 2 & 3 & 1 & 64 & 30.27 & 299.35 \\
\hline \multicolumn{2}{|l|}{3} & 3 & 2 & 1 & 3 & 56 & 32.63 & 314.12 \\
\hline \multicolumn{2}{|l|}{4} & 3 & 1 & 3 & 2 & 40 & 34.93 & 275.13 \\
\hline \multicolumn{2}{|l|}{5} & 1 & 1 & 1 & 1 & 32 & 25.60 & 232.79 \\
\hline \multicolumn{2}{|l|}{6} & 1 & 2 & 2 & 2 & 76 & 24.67 & 266.52 \\
\hline \multicolumn{2}{|l|}{7} & 3 & 3 & 2 & 1 & 48 & 33.42 & 289.64 \\
\hline \multicolumn{2}{|l|}{8} & 2 & 3 & 1 & 2 & 44 & 30.80 & 269.11 \\
\hline \multicolumn{2}{|l|}{9} & 1 & 3 & 3 & 3 & 48 & 24.10 & 236.13 \\
\hline \multirow{4}{*}{$\begin{array}{l}\text { Shelf } \\
\text { Life }(\mathrm{h})\end{array}$} & $K_{1}$ & 52.000 & 38.667 & 44.000 & 48.000 & & & \\
\hline & $K_{2}$ & 50.667 & 65.333 & 56.000 & 53.333 & & & \\
\hline & $K_{3}$ & 48.000 & 46.667 & 50.667 & 49.333 & & & \\
\hline & $R$ & 4.000 & 26.667 & 12.000 & 5.333 & & & \\
\hline \multirow{4}{*}{$\begin{array}{l}\text { Percent } \\
\text { Rebound } \\
\text { (\%) }\end{array}$} & $K_{1}$ & 24.790 & 30.487 & 29.677 & 29.763 & & & \\
\hline & $K_{2}$ & 30.667 & 29.190 & 29.673 & 30.133 & & & \\
\hline & $K_{3}$ & 33.660 & 29.440 & 29.767 & 29.220 & & & \\
\hline & $R$ & 8.870 & 1.297 & 0.094 & 0.913 & & & \\
\hline \multirow{4}{*}{$\begin{array}{l}\text { Density } \\
\left(\mathrm{kg} / \mathrm{m}^{3}\right)\end{array}$} & $K_{1}$ & 245.147 & 254.460 & 272.007 & 273.927 & & & \\
\hline & $K_{2}$ & 274.64 & 293.330 & 270.540 & 270.253 & & & \\
\hline & $K_{3}$ & 292.963 & 264.960 & 272.203 & 268.570 & & & \\
\hline & $R$ & 47.816 & 38.87 & 1.663 & 5.357 & & & \\
\hline
\end{tabular}

Note: A means corn stover moisture content; B means sterilization method; C means inhibitor addition method; $D$ means empty column; $K_{i}(m$ column) means the average value of the sum of the numbers in the $\mathrm{m}$ column and the index value corresponding to "i"; $R$ means range.

(1) Factors affecting the shelf life. From the range of the shelf life ( $R$ value) in Table 3 of the orthogonal experiment, it can be observed that the material sterilization method had the greatest impact on the shelf life of the molding block; the second was the inhibitor addition method. The moisture content of the material had the least impact on it. The experiment to obtain the longest shelf life was experiment No. 6, and the process conditions were $\mathrm{A}_{1} \mathrm{~B}_{2} \mathrm{C}_{2}$.

(2) Factors affecting the percent rebound. From the value of the percent rebound $(R$ value) in Table 3 of the orthogonal experiment, the moisture content of the material had the strongest impact on the percent rebound of the molding block. The second was the material sterilization method. The inhibitor addition method had the least impact on the 
percent rebound of the molding block. The experiment that obtained the lowest percent rebound was experiment No. 9 , and the process conditions were $\mathrm{A}_{1} \mathrm{~B}_{3} \mathrm{C}_{3}$.

(3) Factors affecting density. From the value of the density ( $R$ value) in Table 3 of the orthogonal experiment, it can be observed that the moisture content of the material had the strongest impact on the density of the molding block. The second was the material sterilization method. The inhibitor addition method had the least impact on the density of the molding block. The experiment to obtain the highest density was experiment No. 3, and the process conditions were $\mathrm{A}_{3} \mathrm{~B}_{2} \mathrm{C}_{1}$.

\section{Variance Analysis of Orthogonal Experiment Results}

To explore the degree of influence of various factors on the experimental results, the analysis of variance was introduced on the basis of the range analysis, and SPSS 19.0 was employed to analyze the variance of the orthogonal test results with the shelf life, percent rebound, and density as indicators. The analysis results are shown in Table 4.

Table 4. Orthogonal Experiment Analysis of Variance

\begin{tabular}{|c|c|c|c|c|c|c|}
\hline Indices & Factors & $\begin{array}{c}\text { Sum of } \\
\text { Squared } \\
\text { Deviations }\end{array}$ & $\begin{array}{c}\text { Degree } \\
\text { of } \\
\text { Freedom }\end{array}$ & $\begin{array}{l}\text { Mean } \\
\text { Square }\end{array}$ & $\begin{array}{c}\mathbf{F} \\
\text { Ratio }\end{array}$ & $\mathbf{P}$ \\
\hline \multirow{4}{*}{ Shelf Life (h) } & $A$ & 24.889 & 2 & 12.444 & 0.538 & 0.650 \\
\hline & $\mathrm{B}$ & 1123.556 & 2 & 561.778 & 24.308 & $0.040^{\star}$ \\
\hline & C & 216.889 & 2 & 108.444 & 4.692 & 0.176 \\
\hline & Error & 46.222 & 2 & 23.111 & & \\
\hline \multirow{4}{*}{$\begin{array}{c}\text { Percent } \\
\text { Rebound (\%) }\end{array}$} & $A$ & 122.172 & 2 & 61.086 & 96.480 & $0.010^{*}$ \\
\hline & $B$ & 2.839 & 2 & 1.420 & 2.242 & 0.308 \\
\hline & $\mathrm{C}$ & 0.017 & 2 & 0.008 & 0.013 & 0.987 \\
\hline & Error & 1.266 & 2 & 0.633 & & \\
\hline \multirow{4}{*}{$\begin{array}{l}\text { Density } \\
\left(\mathrm{kg} / \mathrm{m}^{3}\right)\end{array}$} & $A$ & 3492.035 & 2 & 1746.017 & 77.565 & $0.013^{*}$ \\
\hline & $B$ & 2425.984 & 2 & 1212.992 & 53.886 & $0.018^{*}$ \\
\hline & $\mathrm{C}$ & 5.516 & 2 & 2.758 & 0.123 & 0.891 \\
\hline & Error & 45.021 & 2 & 22.510 & & \\
\hline
\end{tabular}

Note: * means significant, which means $\mathrm{P}<0.05$

Table 4 shows that the method of material sterilization had a significant impact on the shelf life of the molding block $(\mathrm{P}<0.05)$. The moisture content of the material and the method of inhibitor addition had no significant impact on the shelf life of the molding blocks. However, material moisture content had a significant effect on the percent rebound of the molding block $(\mathrm{P}<0.05)$. The material sterilization method and inhibitor addition method had no significant impact on the percent rebound of the molding block, while the material moisture content and material sterilization methods did have significant effects on the density of the molding block $(\mathrm{P}<0.05)$. The method of inhibitor addition had no significant effect on the density of the molding block.

Normally, the greater the moisture content of the stover was, the more likely it was to develop mildew (Fig. 6). Zhang et al. (2016) found that for corn stover with different moisture contents in the same treatment, the number of observed moldy sites increased rapidly in the $25 \%$ moisture content group after aerobic storage for $5 \mathrm{~d}$, which was significantly higher than the $20 \%$ moisture content group. However, it was found in this 
experiment that the moisture content of the material had no significant effect on the shelf life of the molding block. In particular, the 50\% moisture content molding block and the $45 \%$ moisture content molding block had a similar shelf life, and the surrounding positions of the $50 \%$ moisture content forming block were the first to exhibit mildew. The reason for this phenomenon may be that the $50 \%$ moisture content is the critical point of "juice extraction" in the compression operation of this stover multistage continuous cold roll forming machine. After the 50\% moisture content of the stover forming block was squeezed, the moisture flowed from the center to the surroundings, which caused the surrounding parts of the stover forming block to be more moist than the central part after the compression was completed (Fig. 7). The central part had a moisture content of less than $50 \%$. The moisture content of the surrounding parts was higher than $50 \%$, but due to better ventilation around the forming block, the moisture content decreased faster, with the result being that the shelf life of the stover forming block with $50 \%$ moisture content was not significantly different from that of the $45 \%$ moisture content stover.

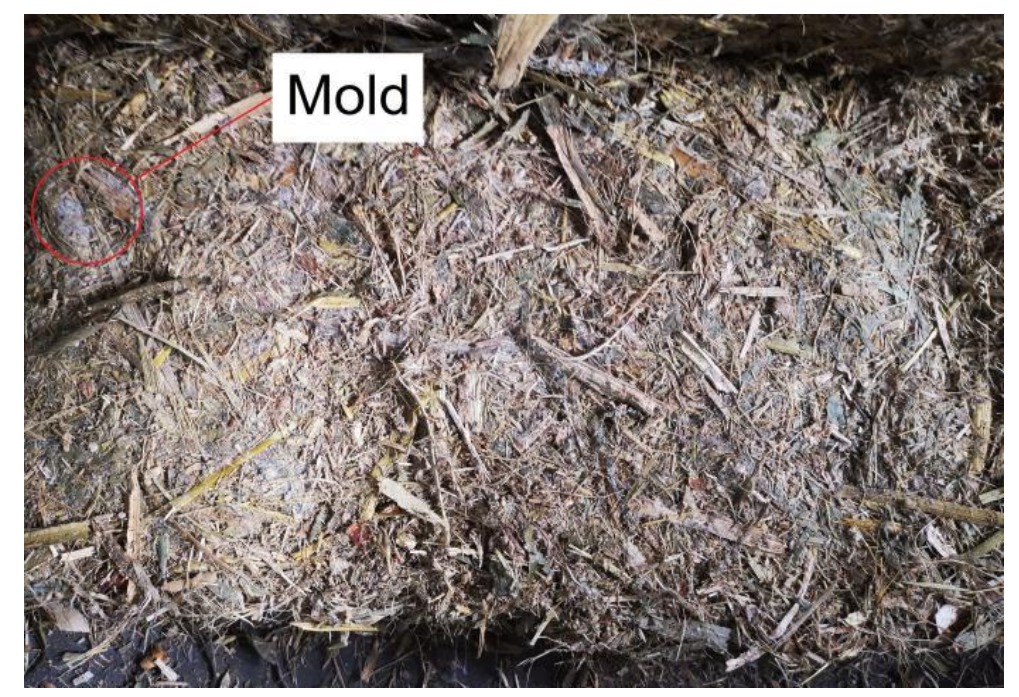

Fig. 6. Moldy stover forming block

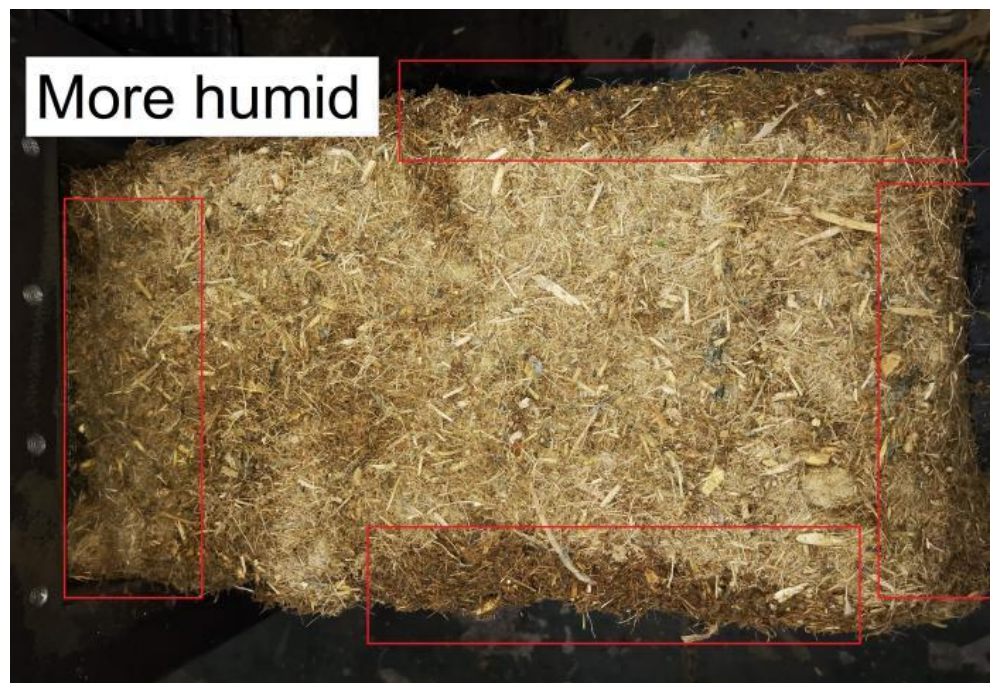

Fig. 7. A 50\% moisture content stover compression molding block with more humid surroundings 


\section{Determination of the Optimal Processing Mode}

Analysis of the comprehensive balance method

The general principle of the comprehensive balance method is as follows: when the importance of each index is different, the selection level should ensure the importance of the index; when the importance of each index is similar, the selection level should grant priority to the main factors or the tendency of the majority. Through the analysis of the comprehensive balance method, the main sequence of the influence of the three factors is sterilization method $>$ material moisture content $>$ inhibitor addition method (Table 5).

Table 5. Comprehensive Balance Analysis

\begin{tabular}{|c|c|c|c|}
\hline Indexes & \multicolumn{3}{|c|}{ Order of the Influence of Three Factors on Each Index } \\
\hline Shelf Life & B & A & C \\
\hline Percent Rebound (\%) & A & B & C \\
\hline Density & A & B & C \\
\hline
\end{tabular}

Note: The order of precedence is from left to right.

This study relied on a stover multistage continuous cold roll forming machine to continuously cold press corn stover with medium-high moisture content without bundles. The purpose was to solve the problem of rapid processing and storage of corn stover with medium-high moisture content. The shelf life index was the most important indicator for this study. For this molding machine, steam sterilization can maximize the shelf life of the molding block. Therefore, the sterilization method factor level was determined as steam sterilization $\left(\mathrm{B}_{2}\right)$. When the sterilization method was determined, the material moisture content had little effect on the shelf life. Therefore, steam sterilization is applicable to corn stover materials with moisture contents of $40 \%$ to $50 \%$. This finding can guide the subsequent optimization and improvement of the forming machine. For example, the machine can be equipped with a steam generator, and a feeding device with a hightemperature steam nozzle installed to carry out high-temperature steam sterilization while feeding the material to improve the quality of the forming block.

The percent rebound and density indicators primarily affect the transportation process of corn stover from the field. The lower the percent rebound is and the higher the density is, the better the transportation performance of the molding block. The moisture content of the material had a significant impact on the density and percent rebound of the molding block. After a comprehensive analysis was conducted, the moisture content of the material was selected as $45 \%\left(\mathrm{~A}_{2}\right)$.

In the experiment, it was found that the inhibitor addition method had no significant effect on the shelf life, percent rebound, and density. Considering that the corn stover forming block at this moisture content stage is mainly used for feed application after being transported to different regions and considering the feed safety and economic cost, the factor level of the inhibitor addition method was determined to be no addition $\left(\mathrm{C}_{1}\right)$.

In summary, based on the stover multistage continuous cold roll forming machine, the optimal processing mode for off-field transportation and storage of the forming blocks is $\mathrm{A}_{2} \mathrm{~B}_{2} \mathrm{C}_{1}$. In other words, the moisture content is $45 \%$, the sterilization method is steam sterilization, and no inhibitor is added. 
Each index of the forming block in the better processing mode

To verify the reliability of the analysis results, experiments were conducted under a combination of better processing methods. Continuous cold rolling was performed on corn stover materials with a moisture content of $45 \%$, steam sterilization, and no inhibitors. The compressed molding blocks were naturally stored in an environment with an average temperature of $32{ }^{\circ} \mathrm{C}$ and an average humidity of $48 \%$. The specific values of each index are presented in Table 6.

Table 6. Each Index of the Forming Block in the Better Processing Mode

\begin{tabular}{|c|c|c|}
\hline Indexes & After Crushing & After Molding \\
\hline Shelf Life $(\mathrm{h})$ & - & 72 \\
\hline Percent Rebound $(\%)$ & - & 24.28 \\
\hline Density $\left(\mathrm{kg} / \mathrm{m}^{3}\right)$ & 67.25 & 309.76 \\
\hline
\end{tabular}

The experimental results showed that the shelf life of the molding block is $72 \mathrm{~h}$, the percent rebound was $24.3 \%$, and the density was $310 \mathrm{~kg} / \mathrm{m}^{3}$. Considering the characteristics of the arid and semiarid continental climate in the pastoral region in northwestern China, the relative humidity in summer is low, and the water loss of the molding block is therefore faster. In actual transportation, as the molding is transported increasingly far into the pastoral area in the northwest, this drying effect is more conducive to prolonging the storage time of the molding block. Therefore, the optimal processing mode $\mathrm{A}_{2} \mathrm{~B}_{2} \mathrm{C}_{1}$, obtained through orthogonal experiments, can largely meet the medium-long distance transportation requirements of more than $2000 \mathrm{~km}$. Thus, corn stover from the HuangHuai-Hai region of China can be transported to pastoral areas in northwestern China.

\section{CONCLUSIONS}

1. Based on the stover multistage continuous cold roll forming method, a method suitable for the transportation and storage of corn stover with medium-high moisture content was proposed, and the feasibility of this method was verified. This approach provides a new method for rapid off-field transportation and storage of corn stover in the HuangHuai-Hai area of China.

2. Orthogonal experimental results showed that the steam sterilization method can increase the shelf life of the molding block. The percent rebound and density of the molding block are primarily affected by the moisture content of the material followed by the effect of the sterilization method.

3. The molding block can be stored for $72 \mathrm{~h}$ without mildew in an environment with an average temperature of $32{ }^{\circ} \mathrm{C}$ and an average humidity of $48 \%$ during the day. The percent rebound was $24.3 \%$, and the density can reach $310 \mathrm{~kg} / \mathrm{m}^{3}$ after the completion of rebound. The molding block can meet the requirements of medium-long distance transportation.

4. The continuous cold roll forming of corn stover with medium-high moisture content without bundles was realized, which provides a theoretical basis and reference for further research investigating the rapid and low-cost off-field transportation of biomass stover and efficient medium-long distance transportation, storage, and reuse. 


\section{ACKNOWLEDGMENTS}

The authors are grateful for the support provided by the China National Key Research and Development Plan, Grant No. 2016YFD0701300.

\section{REFERENCES CITED}

Bi, Y., Gao, C., Wang, H., Wang, P., and Wang, Y. (2019). "Research on the present situation and corresponding strategies of off-field straw collection and comprehensive utilization in China," Chinese Journal of Agricultural Resources and Regional Planning 40(9), 1-11. DOI: 10.7621/cjarrp.1005-9121.20190901

Cong, H., Li, M., Li, R., Wang, K., He, W., and Zhao, H. (2009a). "Design of 4YQK-2 combine harvester for corn and straw ensilage," Transactions of the Chinese Society of Agricultural Engineering 25(10), 96-100. DOI: 10.3969/j.issn.10026819.2009.10.017

Cong, H., Li, R., Han, X., Li, M., Fan, X., and Zhao, H. (2009b). "Design of automatic control system on baling apparatus for ensilage maize combine," Transactions of the Chinese Society for Agricultural Machinery 40(11), 42-45.

Dong, Y., Li, Z., Wang, R., Bu, X., Fu, J., and Dong, X. (2018). "Study on the problems and countermeasures of returning wheat and corn stalks into the soil in North China," China Soil and Fertilizer 2018(1), 159-163. DOI: 10.11838/sfsc.20180126

Gao, D., Wang, D., Li, J., Liu, Y., and Qiao, X. (2015). "Design and test of logarithmic spiral round baler chamber," Transactions of the Chinese Society for Agricultural Machinery 46(7), 118-121. DOI: 10.6041/j.issn.1000-1298.2015.07.018

Guo, B., He, J., Wang, D., Zhao, J., Li, W., and Liu, Q. (2018). "The research situation and development tendency of straw baling machine," Journal of Agricultural Mechanization Research 40(1), 264-268. DOI: 10.13427/j.cnki.njyi.2018.01.049

Guo, L., Wang, D., Tabil, L. G., and Wang, G. (2016). "Compression and relaxation properties of biomass for briquetting," Biosystems Engineering 148, 101-110. DOI: 10.1016/j.biosystemseng.2016.05.009

Huang, Q., Xiao, H., and Sun, B. (2007). Steel Rolling Machinery Design, Metallurgical Industry Press, Beijing, China.

Iskakov, R. M., Iskakova, A. M., Issenov, S. S., Beisebekova, D. M., and Khaimuldinova, A. K. (2019). "Technology of multi-stage sterilization of raw materials with the production of feed meal of high biological value," Journal of Pure and Applied Microbiology 13(1), 307-312. DOI: 10.22207/JPAM.13.1.33

Kaliyan, N., Morey, R. V., and Schmidt, D. R. (2013). "Roll press compaction of corn stover and perennial grasses to increase bulk density," Biomass and Bioenergy 55, 322-330. DOI: 10.1016/j.biombioe.2013.02.031

Liu, F., Li, J., Kan, Z., and Wen, B. (2019). "Experimental study on compression characteristics of crushed corn straw," Journal of Agricultural Mechanization Research 41(1), 169-173. DOI: 10.13427/j.cnki.njyi.2019.01.030

Liu, P., Luo, L., Li, H., Han, L., Wei, W., and Zhang, S. (2016). "Theory and device design of multi-stage roller forming for straw," Transactions of the Chinese Society for Agricultural Machinery 47(1), 317-323. DOI: 10.6041/j.issn.10001298.2016.S0.049 
Liu, X., Hou, J., Li, W., Feng, W., and Liu, J. (2017). "Design of feeding type round baler for 53.2017.07.006

Murata, H., Mitsumatsu, M., and Shimada, N. (2008). "Reduction of feed-contaminating mycotoxins by ultra straw," Journal of Chinese Agricultural Mechanization 38(7), 29-33. DOI: 10.13733/j.jcam.issn.2095-55violet irradiation: An in vitro study," Food Additives \& Contaminants: Part A 25(9), 1107-1110. DOI: 10.1080/02652030802057343

Ning, T., Yu, G., Chen, Z., Yuan, X., Liu, W., and Pi, S. (2016). "Design and experiment of roller briquetting machine with plungers," Transactions of the Chinese Society for Agricultural Machinery 47(5), 203-210. DOI: 10.6041/j.issn.1000-1298.2016.05.028

Ouyang, S., Hou, S., Zhao, L., Tian, Y., and Meng, H. (2011). "The research progress in biomass annular mold forming for fuel technology," Renewable Energy Resources 29(1), 14-18. DOI: 10.13941/j.cnki.21-1469/tk.2011.01.004

Przybył, J., Wojcieszak, D., Kowalik, I., and Dach, J. (2018). "Influence of the harvesting and ensilage technology on the quality of maize straw silage," BIO Web of Conferences 10, Article number 02027. DOI: 10.1051/bioconf/20181002027

Qian, Y., Zhang, Y., Du, J., Kong, X., Chang, Z., and Ye, X. (2019). “Advantages and disadvantages analysis of comprehensive utilization of straw in Jiangsu Province and countermeasure suggestions for collection-storage-transportation system," Transactions of the Chinese Society of Agricultural Engineering 35(22), 154-160. DOI: 10.11975/j.issn.1002-6819.2019.22.018

Shinners, K. J., Binversie, B. N., and Savoie, P. (2003). "Harvest and storage of wet and dry corn stover as a biomass feedstock," ASAE Paper No. 036088.

Tan, F., He, L., Zhu, Q., Wang, Y., Hu, G., and He, M. (2019). "Characterization of different types of agricultural biomass and assessment of their potential for energy production in China," BioResources 14(3), 6447-6464. DOI: 10.15376/biores.14.3.6447-6464

Tian, Y., Xu, Y., Hou, S., Zhao, L., Yao, Z., and Meng, H. (2015). "Effect of storage methods on properties of corn straw after storage," Transactions of the Chinese Society of Agricultural Engineering 31(9), 223-229. DOI: 10.11975/j.issn.10026819.2015.09.034

Tumuluru, J. S., Wright, C. T., Hess, J. R., and Kenney, K. L. (2011). “A review of biomass densification systems to develop uniform feedstock commodities for bioenergy application," Biofuels, Bioproducts and Biorefining 5(6), 683-707. DOI: 10.1002/bbb.324

Wang, F., Chen, Z., Wang, J., Wang, X., and Chen, F. (2009). "Design and experiment of 4YF-1300 large rectangular baler," Transactions of the Chinese Society for Agricultural Machinery 40(11), 36-41.

Wang, G., Jiang, Y., Li, W., and Yin, X. (2016a). "Process optimization of corn stover compression molding experiments based on response surface method," Transactions of the Chinese Society of Agricultural Engineering 32(13), 223-227. DOI: 10.11975/j.issn.1002-6819.2016.13.032

Wang, R., Wei, K., Liu, Y., Chen, Z., Ma, F., and Liu, D. (2016b). “Optimization of process parameters for multi-frequency rapid compression molding of corn stalk silk used for forage," Transactions of the Chinese Society of Agricultural Engineering 32(21), 277-281. DOI: 10.11975/j.issn.1002-6819.2016.21.038

Wu, J., Huo, L., Zhao, L., Yao, Z., Meng, H., and Hou, S. (2016). "Experiment research on maize straw equilibrium moisture for secure storage," Journal of Chinese 
Agricultural Mechanization 37(11), 73-77. DOI: 10.13733/j.jcam.issn.20955553.2016.11.018

Xia, X., Sun, Y., Wu, K., and Jiang, Q. (2014). "Modeling of a straw ring-die briquetting process," BioResources 9(4), 6316-6328. DOI: 10.15376/biores.9.4.6316-6328

Xie, W., Li, X., Fang, Z. W., Quan, W., Luo, H., and Wu, M. (2019). "Design of compound machine for rice straw collecting and continuous baling," Transactions of the Chinese Society of Agricultural Engineering 35(11), 19-25. DOI: 10.11975/j.issn.1002-6819.2019.11.003

Xiong, C., Xie, Z., Yi, W., Xu, R., and Yao, J. (2010). "Study on basic characteristics of crop straw/stalk used as biomass energy resources," Southwest China Journal of Agricultural Sciences 23(5), 1725-1732. DOI: 10.16213/j.cnki.scjas.2010.05.009

Zhai, S. (2013). "Main problems and improvement suggestions in the practical application of straw forming technology," Agricultural Development and Equipment 2013(5), $72-73$.

Zhang, L., Li, Y., Zhang, W., Yang, J., Zhang, G., and Zhang, Y. (2016). "Effect of different microbes and their combination on controlling moulds of corn stalk," Journal of Northeast Agricultural University 47(12), 74-85. DOI: 10.19720/j.cnki.issn.1005-9369.2016.12.010

Zuo, X., Wang, H., Wang, Y., Wang, L., Jing, L., and Wang, D. (2015). "Estimation and suitability evaluation of corn straw resources in China," Chinese Journal of Agricultural Resources and Regional Planning 36(6), 5-10. DOI: 10.7621/cjarrp.1005-9121.20150602

Article submitted: August 13, 2020; Peer review completed: October 10, 2020; Revised version received and accepted: October 26, 2020; Published: October 28, 2020.

DOI: 10.15376/biores.15.4.9539-9554 